\title{
The Discussion of Cross Specialties Comprehensive Professional Training Mode Based on VBSE
}

\author{
Hongqin Li \\ International Business College of Shandong Institute of Business and Technology, Yantai, Shandong, China
}

(weiqin0725@126.com)

\begin{abstract}
At present, the practice situation of college students is worrying. But enterprises are very popular to college students with experience. How to improve the practice quality of college students has become an important issue in colleges and universities. The cross specialties comprehensive professional training mode based on VBSE cleverly solves the problem. It moves virtual business society environment into the campus, enhances the students' cognitive ability of enterprises. The training improves the students' real operation ability, analysis of the question and problem-solving ability. It completes the transformation of the college students from designed to senior applied talents of refined.
\end{abstract}

Keywords—virtual business society environment, cross specialties, electronic journals

\section{VBSE 跨专业综合实训模式的探讨}

\author{
李红芹 \\ 山东工商学院国际商学院，烟台，山东，中国
}

摘 要 目前, 大学生实习现状令人堪忧, 企业对有实习经验的大学生却格外青崃。如何提高大学生实习质量成为各高校的重要 议题。VBSE 跨专业综合实训模式的出现巧妙地解决了这个问题, 它将虚拟的商业社会环境搬进校园, 通过实训提高学生对企业的认 知能力, 实级操作能力以及分析问题, 解决问题的能力, 完成由专到精的高级应用型人才的转变[1]。

关键词 VBSE, 跨专业, 电子杂志

\section{1. 引言}

VBSE 是用友新道科技有限公司推出的通过对不同形 态组织典型特征的抽取, 营造一个由多家模拟制造企业和 外围服务机构构成的虚拟商业社会环境, 让学生在虚拟的 市场环境、商务环境、政务环境和公共服务环境中, 根据 现实工作内容、管理流程、业务单据, 结合业务规则, 将 经营模拟与现实工作接轨, 进行仿真经营和业务运作, 以 实现宏观微观管理、多人协同模拟经营和多组织对抗, 满 足多专业学习与实践一体的实训产品。

VBSE 是一款跨专业实训产品, 很多同学将“跨专业” 误解为“换专业”, 学财务管理的申请销售岗位, 学市场营 销的申请会计岗位。实际上这里的“跨专业”是指在实训中 包含了多个专业的业务, 比如财务管理, 会计, 市场销售, 信息管理，金融等等，学生在模拟商业环境中可以分角色， 面向企业业务, 面向实际问题, 面向流程, 与他人配合完 成项目 [2]。

\section{2. 实施 VBSE 跨专业综合实训模式的必要性}

目前大学生就业存在一种怪象: 学生毕业找不到工作, 而企业的发展却急需大量人才。导致这种怪象的原因很多, 学生能力达不到企业需求是一个重要方面。企业在招聘人 才时希望学生已经有实际的工作经验, 来了即可上岗, 很 多高校业已认识到这个问题, 竭尽所能为学生创造机会, 在制定教学计划时为学生安排实习周, 建立实习教学基地, 让学生有机会把所学的专业知识应用到实际工作中, 获得 工作经验。尽管高校在学生实习方面做了大量的工作, 但 是目前大学生的实习现状难以令人满意。在 2012 年 5 月 24 日举行的北京大学 “中国经济学教育论坛” 上, 北大校长 助理黄桂田提出: $80 \%$ 的大学生实习是跑腿打杂, 很少有 人被单位最终接纳就业。大学教学、学生学习的秩序却遭 到了冲击。黄桂田认为“实习影响大学生学业”, 呼呼在场 的全国各高校经济学院负责人共同禁止学生参加实习, 以 
矫正这种“变态工作需求”。从企业的角度来分析, 很多企 业不愿意接受实习大学生, 将工作岗位交给实习生也是可 理解的, 一方面实习生实际操作能力差, 对专业知识的掌 握不够扎实, 不能满足岗位的需求, 影响了企业正常的工 作秩序; 另一方面, 个别大学生实习态度不端正, 工作不 积极, 缺乏主动性, 也使得企业不愿接纳实习大学生。而 对于黄桂田的观点, 中国教育新闻网的回应是: 其实, 真 正的问题不是要“禁止实习”, 而是要提高实习的质量, 让 学生们在实习的岗位上能学到学校所不能学到的东西, 学 到真本领。由此可见, 禁止实习不是办法, 如何提高大学 生实习质量才是高校真正需要解决的问题。

既然学生进入企业达不到实习预期的目标, 那么我们 是否可以考虑将虚拟化的企业搬进校园, 为学生构建一个 虚拟商业社会环境, 按照真实企业的运转机制设置岗位, 根据真实企业正常业务开展的流程制定实习任务, 定岗到 人, 通过岗位模拟来熟练掌握专业知识, 通过模拟了解职 场人实际工作呢? 实践证明这是可以的, VBSE 跨专业综 合实训平台就是这样的一款产品。

\section{VBSE 跨专业综合实训模式实施要点}

\section{1 实训场地的布置}

在积极创办 “应用型”人才高校的学校政策指引下, 山 东工商学院商学实验中心按照 “把企业搬进校园” 的建设思
路, 搭建了与当前商业社会运行环境高度仿真的实验教学 环境——跨专业综合实训室, 配备了电脑, 实验桌椅, 多 媒体设备, 圆弧形的面试场地, 真正使“把企业搬进校园” 成为可能, 为实现“院校人才培养”与“社会商业发展”的协 调同步提供了条件。

\section{2 实训岗位设置}

VBSE 跨专业综合实训的基本组织机构为模拟企 业, 模拟企业的数量可根据实习场地规模决定。每个模 拟企业的岗位设置如图 1 所示, 共包含七个部门, 十八 个岗位。根据实训经验, 财务会计, 出纳的工作任务较重, 可各备两名, 另外可设一名 CEO 兼职作为培养干部, 辅助 CEO 进行企业管理, 这样一个模拟企业的岗位编制大约在 18 21 人。由于企业是模拟的, 不需要真实地进行企业生 产, 所以生产工人岗位不需要安排实训人员, 但是, 在进 行薪资计算时, 为了模拟真实企业, 可加入生产工人部分 的工资计算。在实训过程中, 除了模拟企业的岗位设置外, 还应包括一些外围服务单位, 以保证业务的正常流转, 具 体包括: 广告公司 (负责广告业务), 会展中心 (负责组织 商品交易会), 银行 (负责五险一金处理, 薪酬发放, 企业 购买支票和货款回收), 税务 (企业购买发票的服务机构), 社保中心 (负责社会保险缴纳与核算)。

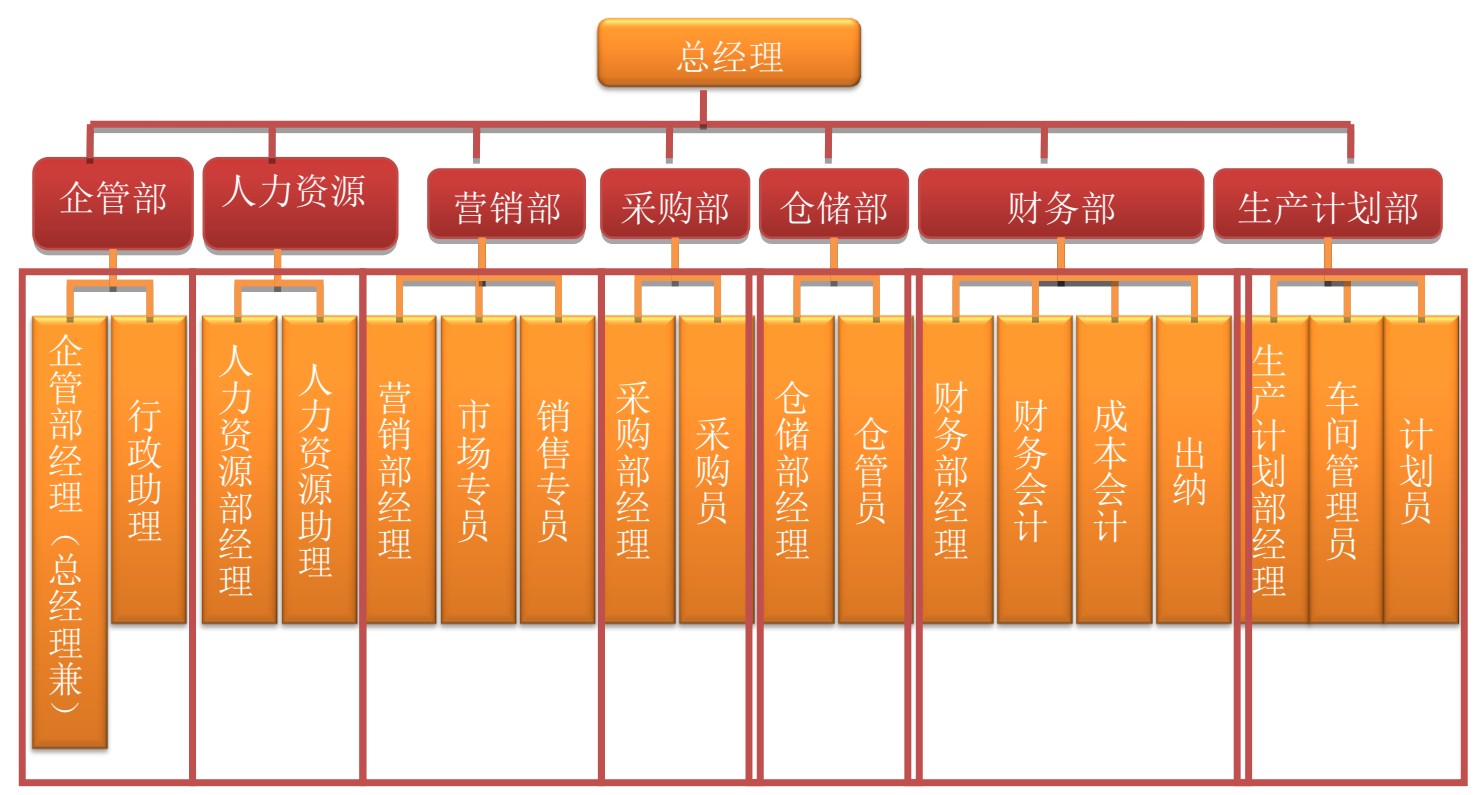

图 1 模拟企业岗位设置 


\section{3 实训进度安排}

为了能让学生真实地体验企业工作状态, 实训按照每 天八小时工作制执行, 学生打卡上下班, 实训天数和内容 可根据学校规定的实习时间弹性设置。实训采用两种模式: 手工模拟和信息化模拟结合进行, 两种模式下企业的业务 处理流程可以相同。为了避免业务重复性带来的弊端, 可 在广告费的投放与竞单上做些设置: 手工方式下各模拟企 业的广告费相同，因此可以拿到的销售订单也是相同的; 信息化下广告投放学生需要根据企业具体情况, 结合企业 的现状及发展目标来确定广告投放金额; 广告费不同, 相 应的后续操作也就不同, 增加了一个竞单的过程, 类似于 企业沙盘模拟, 这样可以加大模拟企业业务开展的难度, 提高学生的兴趣, 另外也可作为各模拟企业经营结果的一 个评价标准。由于实训初期, 学生对竞单没有经验, 所以 实训时可考虑先手工模拟后信息化模拟。

\subsection{1 实训流程}

实训按照以下流程进行:

(1) 组织学生答题: 获得 CEO 竞选名单;

（2）指定企业外围人员: 可由学生自愿报名, 也可由 指导教师指定;

（3）竞选 CEO: 根据学生答题成绩获取候选人名单, 也可由学生推荐或毛遂自荐, 然后所有的候选人进行演讲, 最后由学生投票获得最终的 CEO 人选, 录入实训软件;

（4）指定 CHO (人力资源部经理): 一般由 CEO 指 定;

(5) 各模拟企业由 CEO 和 CHO 负责组织招聘: 各模 拟企业制作招聘广告, 组织现场招聘, 学生到各个企业参 加面试;

（6）各企业指定岗位人员名单并将其录入实训系统, 然后由 CEO 开启企业业务。

\subsection{2 模拟企业业务内容}

企业业务内容包括主线和辅线两部分。

主线按照广告投放——参加商品交易会——编制生产 计划——生产——产品完工入库一一销售发货——货款回 收一一库存盘点的流程进行; 辅线业务主要是采购, 按照 签订采购合同——采购入库——材料款支付的流程进行; 另外实训中还可加入人力资源管理业务, 进行薪酬的核算 与发放以及社保的缴纳与核算。

每项业务涉及的部门和处理流程在用友的实验辅导资 料中均有具体的介绍和说明, 可以帮助学生快速进入角色。 另外, 在软件中, 还备有岗前培训以及每个岗位相关的业
务操作视频, 可以帮助学生迅速有效地解决操作中存在的 问题。

\section{4 学生成绩考核方式}

学生成绩由以下部分组成:

(1) 系统考核

系统内自带 360 评价体系, 学生利用该体系可以给有 业务往来的岗位同学打分, 可以查看其他岗位同学对自己 的评价。

(2) 工作态度考核

对学生日常实训过程中的表现进行评价, 指导教师可 通过学生提交的岗位日志, PPT 分享过程的表现进行考核。

（3）企业管理考核

模拟企业的 CEO 和 CHO 根据企业制定的管理制度对 员工进行评价打分, 具体评价标准以企业为准, 比如加班 员工应当给予适当的奖励等等。

(4) 外围考核

外围对各个企业接触人员打分, 各个企业业务人员对 外围进行评价。

（5）企业经营结果考核

指导教师根据信息化实训的经营结果为各个模拟企业 打分。

各部分考核结果在总成绩中所占的比例可自行确定。

\section{VBSE 跨专业综合实训模式实施意义}

首先, VBSE 实训平台为学生提供了实习机会, 解决 了学生实习难的问题。学生从应聘某企业开始, 进入企业 切身感受岗位工作, 定岗到人, 挂牌上岗, 每个岗位都有 自己的工作和任务, 小到单据的填列, 大到决策任务的下 达, 一应俱全, 避免了实习流于形式。订单, 合同, 账簿 的填写需要严格遵循企业相关规定, 仿真货币、产品、营 业执照、公章等的使用, 让学生可以充分体验真实的商业 环境。

其次, 锻炼了学生, 让学生获得了一些在课堂上体验 不到的能力, 训练了在现代商业社会中从事经营管理所需 的综合执行能力、综合决策能力和创新创业能力, 感悟复 杂市场营销环境下的企业经营, 学会工作, 学会思考, 从 而培养自身的全局意识和综合职业素养[3]。

（1）学生自主选择岗位, 通过竞聘上岗体悟真实的面 试: 假如实训中有 10 家模拟企业, 那么实训学生人数将达 到 200 人, 200 人同时在会场中找工作, 可以让学生亲身 体验人才交流会现场气氛, 并且通过面试认识到专业知识 的重要性, 发现自身的不足, 给其以压力和紧迫感。

(2) 通过合同处理了解合同签订过程: 实训中发现很 
多同学不知道合同的甲乙方是谁, 填写合同时随意写。有 的同学认为自己企业是甲方, 实际上合同上的甲方应是出 资方, 在填写销售合同时, 自己企业应为乙方而不是甲方。 另外, 很多同学不知道合同上如何盖章, 在甲乙方处盖章 后就完成了合同的签订, 忽略了骑缝章。所谓的骑缝章, 顾名思义应该骑缝, 并且应该是骑住所有缝, 即盖完骑缝 章后合同的每一页都应该均有红印, 并且第一页和最后一 页最好同时有字, 不应存在漏页的情况。合同展开应该能 够将骑缝章还原成原章, 只有这样才是比较规范的骑缝章, 才能发挥骑缝章的作用。

（3）通过分享锻炼了 PPT 制作能力和表述能力: 信 息时代的企业在经营管理上注重员工培训, 经常组织员工 进行经验交流, 这就要求员工必须具备一定的 PPT 制作能 力和讲解能力。但是, 在大学的学习生活中, 大部分课程 都是任课教师讲授, 学生很少有这样的表现机会。为了让 学生收益最大化, 汲取更多的知识, 实训中可安排模拟企 业各部门通过 PPT 分享工作经验与体会, 通过彼此的交流 获取信息。对这来之不易的机会, 学生非常珍惜, 做的非 常认真, PPT 制作效果令人耳目一新, 讲解能力以及表述 能力也得到了充分的锻炼。

(4) 通过制作电子杂志锻炼了自学能力: 电子杂志是 2003 年逐渐兴起的一种比较新的媒体表现形式, 以 FLASH 为主要载体, 将图像, 文字, 声音、视频等相互动态结合 呈现给读者。学生的教学计划中没有这方面的内容介绍, 实训任务中的企业文化建设却要求学生制作电子杂志, 尽 管时间比较仓促, 很多小组还是克服困难, 完成了企业的 第一本电子杂志, 效果出乎意料。由于专业教师忙于指导 专业操作, 企业文化建设内容完全交由学生, 所有的工作 都由学生自学完成, 不做操作指导, 这项工作充分锻炼了 学生的自学能力。

（5）通过信息化实训掌握了 ERP 软件的基本操作: VBSE 信息化实训底层的财务软件为用友 ERP-U8 V10.1, 业务涉及的模块包括了总账, 工资, 固定资产, 应收, 应 付, 采购, 销售, 库存, 存货等, 除了财务管理专业和会 计专业的学生学习过《会计软件的应用》, 其他专业的学生 没有这方面的基础, 此软件的使用可加深学生对 ERP 软件 的认识, 锻炼学生的软件操作能力。

通过实训, 我们发现学生的潜力是可挖掘的, 无限量 的。由于日常授课中缺乏这样的机会, 学生的这些潜能无 法展现, 无形中给埋没了。实训可使学生更加清楚地认识 自己, 发现自己的潜能, 更好地规划自己的人生。

再则, 可以解决大学生培养中存在的“专业井”问题。 所谓的“专业井”是指学生在自己所修的专业上知识越来越
深入, 但是对其他专业基本不了解, 好比井底之蛙“坐井观 天”。VBSE 实训可以提高学生的综合思维能力, 将学生 培养成有全局观的实务型岗位管理人员。

最后, 从教师的角度来看, VBSE 给了高校教师一次 很好的锻炼机会。

(1) 现阶段高校的发展要求教师教学科研两手抓, 同 时还应具备一定的实践操作能力。但是, 大部分教师根本 没有时间深入企业，更谈不上熟悉企业的实际业务。VBSE 实训可以帮助教师弥补这方面的欠缺, 有机会接触企业的 实际业务。

(2)教学方法改革是高校教师不解追求的目标, VBSE 实训让教师的角色从以讲授知识为主, 转变为以策划教学 内容, 创设学习情境, 配置学习资源, 引导学习方向, 指 点学习疑难, 监控学习过程, 评估学习效果为主, 从台上 的主角转变为台下的导演[2]。

（3）由于实训是跨专业的, 指导教师来自不同专业, 教师之间可以了解彼此专业之间的关联性, 解决日常教学 中存在的知识重复或者知识脱层的现象, 互相交流, 互相 学习, 实现整体教学能力的提升。

\section{5. 结束语}

VBSE 跨专业综合实训模式解决了学生实习难的问 题, 培养了学生的岗位胜任能力, 使学生在进入企业之后 有能力胜任岗位工作, 提高了学生的综合素质, 突破了高 校实践教学的瓶颈, 在高校的人才培养中必将发挥重要的 作用。

\section{参考文献(References)}

[1] W.Y. JIANG, K. SU and F. YUAN, Research on system construction of the comprehensive practical training for cross management specialties, Laboratory Science, vol.15, pp. 163-166, 2012.

[2] H. F. WU and D. P. ZOU, Construction of experimental teaching system based on applicative talents training: taking the practice of economic management specialty of Shandong Institute of Business and Technology as an example, Journal of Shandong Institute of Business and Technology, vol.26, pp. 113-115, 2012.

[3] S. Y. KANG, Practice teaching mode of institute of finance and economics in information age: virtual business society environment, China Management Informationization, vol.15, pp. 103-104, 2012. 